\title{
Announcements
}

\section{Ninth Annual Meeting of the Society for the Study of Reproduction}

The Meeting will be held at the University of Pennsylvania, Philadelphia, Pennsylvania, Wednesday to Saturday, August 11-14, 1976. The program includes sessions devoted to research papers, a symposium on 'Hormonal Control of Parturition', and the annual Carl Hartman lecture. For additional information please contact: Mr. ClaUdE CRUSE, Business Manager, The Society for the Study of Reproduction, 113 North Neil Street, Champaign, IL 61820 (USA).

Third International Symposium on the Pharmacology of Thermoregulation

The Symposium will be held at the Banff Centre, Banff, Alberta Canada on September 14-17, 1976. For further details, registration and reservation forms please write to the organisers: Prof. K.E. CoopeR, Division of Medical Physiology, Faculty of Medicine, The University of Calgary, Calgary, Alberta, T2N 1N4 (Canada). Prof. E. ScHÖNBAUM, Peelkensweg 4, 4274 Venhorst N.Br. (The Netherlands). Prof. P. LomAx, Department of Pharmacology, UCLA School of Medicine, Los Angeles, CA 90024 (USA). As was true with the previous two symposia, the proceedings of the third symposium will again be published by S. Karger, Basel. 